\title{
Students' Thinking Process in Solving Abstraction Problems in Mathematics: A Case Study on Limited Test of Development Research Instrument
}

\author{
Izwita Dewi, Nurhasanah Siregar, Ade Andriani \\ Medan Indonesia
}

\begin{abstract}
Abstraction is an activity performed in daily life and the ability needs to be developed, especially in mathematics learning. The information on how students solve problems is important for teachers to consider the strategies to use in helping the students. This research was carried out due to the answers' variations discovered in abstraction problems. Therefore, it aimed to investigate students' thinking processes in solving problems. The research was a combination of the Sequential Explanatory Design model that used both quantitative and qualitative data collection and analysis methods, while the subjects used were 33 students of seventh grade. The result showed guessing and drawing was used to solve the abstraction problems, but only one student employed patterns and pictures in the process. Consequently, training students on critical thinking skills utilization to solve abstraction problems easily was suggested in mathematics learning.
\end{abstract}

Keywords: Abstraction Ability, Critical Thinking, Skills

\section{Introduction}

Mathematical knowledge consists of a collection of schemas, but only little is known about how this exists in a person's mind. When giving a problem to someone, the schema or thought process is possibly not observed directly. However, observations on these individuals are estimated to see and understand the phenomena that arise due to the problems.

Thinking is a person's mental activity to decide a problem that needs to be solved and also find the appropriate solution. There are various ways to solve problems, Sheffield and Cruikshank (1996) stated five which include 1) dabbling, 2) making patterns, 3) making and compiling lists systematically, 4) creating and using images, and 5) excluding possibilities. This is supported by Montague (Walker: 2007) which reported that a good problem solver often uses various processes and strategies.

One of the thinking abilities in mathematics is an abstraction because it is the process of connecting an idea with a mathematical concept. The development of mathematics is seen as a series of abstractions that are always increasing or expanding the subject matter. Also, abstraction is a process of constructing the knowledge needed by students and the teachers to assist students in building their understanding. In addition, for teachers to consider the strategies to be used, the information on how students construct personal understanding is important. Miller \& Mercer, (1993) stated the abstraction process helps both students with low mathematical ability and those having learning difficulties. Conversely, abstraction tends to also be a failure in mathematics learning (Ferrari: 2003).

The limited test of mathematical abstraction ability instruments conducted for a research development led to the idea of this paper. Furthermore, one of the three questions tested was not answered correctly by any student, besides there were five variations/types of answers from that one problem. Based on this, two thoughts were conceived namely first, do students have no enough time to solve problems? This was answered when interviewed which was after the written test. The students were given enough time to solve the same problem but not all were consistent with how to get the answer, although some realized the answer was incorrect. Hence, the phenomenon that often occurs is not the lack of required time. Second, what was the thinking process used or how did they obtain answers to the mathematical abstraction problems? This question is the main focus of this paper.

\section{Method}

This research was a combination of the Sequential Explanatory Design model that used quantitative data collection and analysis in the first stage, followed by using the qualitative method to strengthen the results. The quantitative aspect examined was students' mathematical abstraction ability. Meanwhile, the qualitative was how students obtained answers to the tests conducted. The subjects used were 33 students of seventh grade, which were chosen for interviews to represent each answer type that came from the written test. Because the thinking process is a mental activity, the students were observed through the interviews conducted to explore how they solve mathematical abstraction problems. 


\section{Results and Discussion}

Abstraction ability test was given to 33 students of seventh grade in Junior High School in the city of Serbelawan, North Sumatra based on the following problems:

"If two lines met at one base point will form an angle, so if there are 15 lines, how many angles were formed?"

After analysis was conducted, 5 different answer types were discovered, and 3 students provided none. Based on the results, 5 students were interviewed as research subjects and the description of their answers was as follows.

Subject 1 (S1) represented the students that stated 30 angles are potentially formed from 15 lines having the same starting point and 16 persons also provided a similar answer as the S1 (Figure 1). They solved the problem without using pictures and $15 \times 2=30$ was the reason provided.

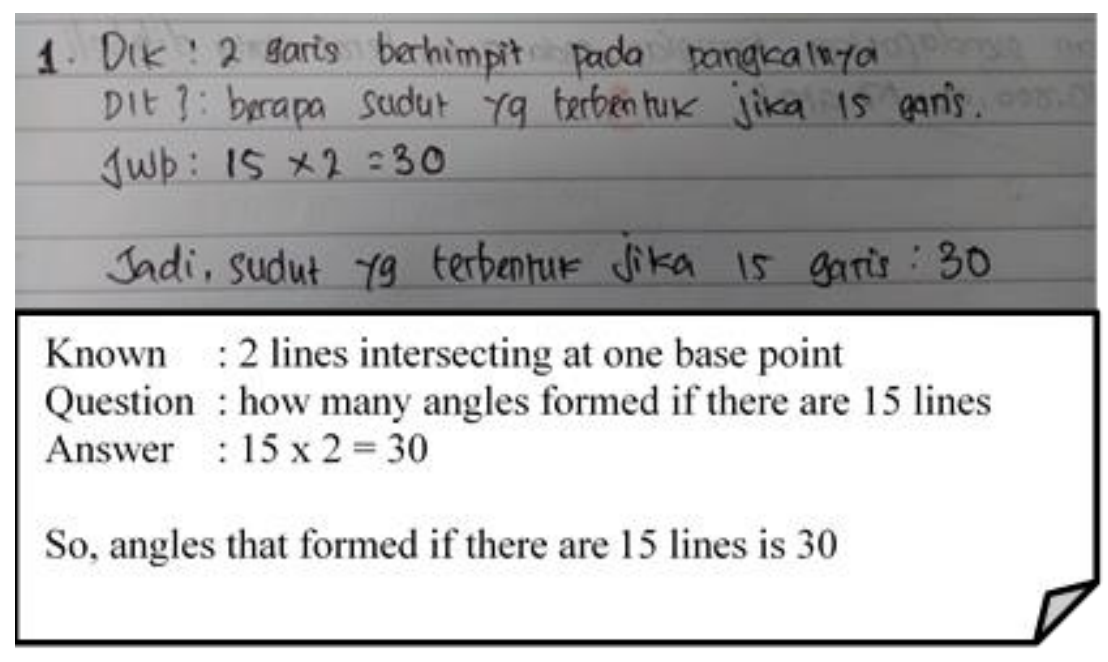

Figure 1. Written Answer from Subject 1

Based on the answers, an interview was then conducted.

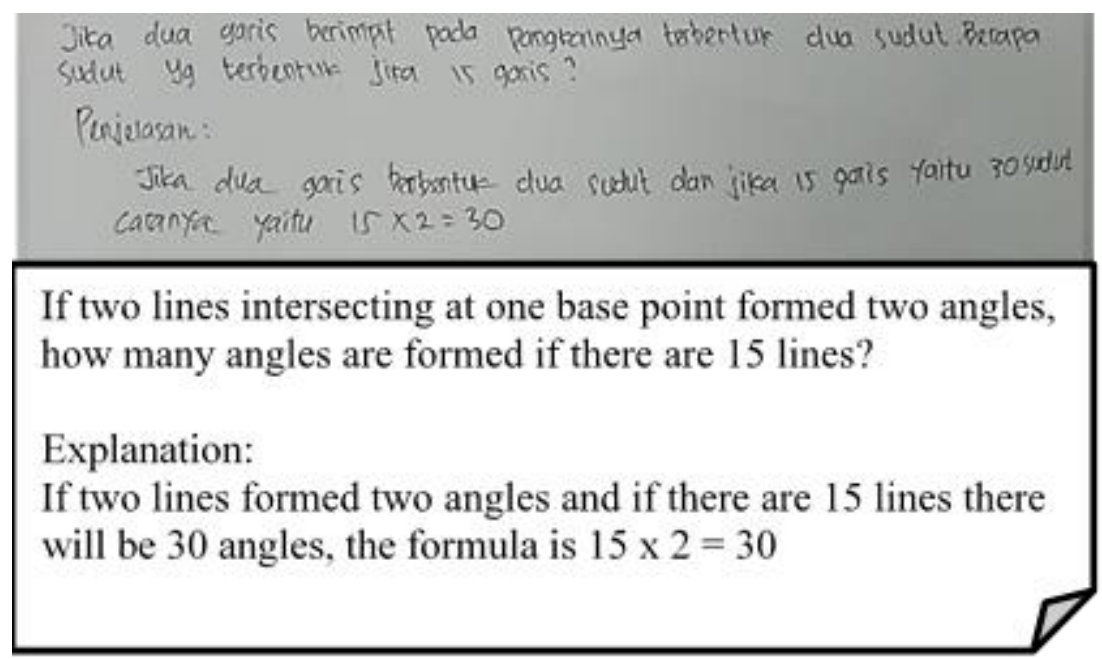

Figure 2. Interview Answer Sheet from Subject 1

The S1 interview answer was the same as that of the written test, which was 15 × $2=30$. When asked why they did not use a picture, $\mathrm{S} 1$ said there was no need for a picture because it can already be imagined. The answer was just based on guessing, and in case the problem is resolved with the help of pictures, a different answer tends to be obtained, but S1 persisted with the initial answer. When asked "did you think there are still other ways you can solve this problem?" S1 response was no. 
Subject 2 (S2) represented 5 students that answered according to Figure 3. To solve the problem initiated by S2, first, draw 15 lines having the same starting point. Then they wrote 14 angles were produced from the 15 lines, but no reasons were provided as support. Next, an interview was conducted to determine how the answer was obtained.

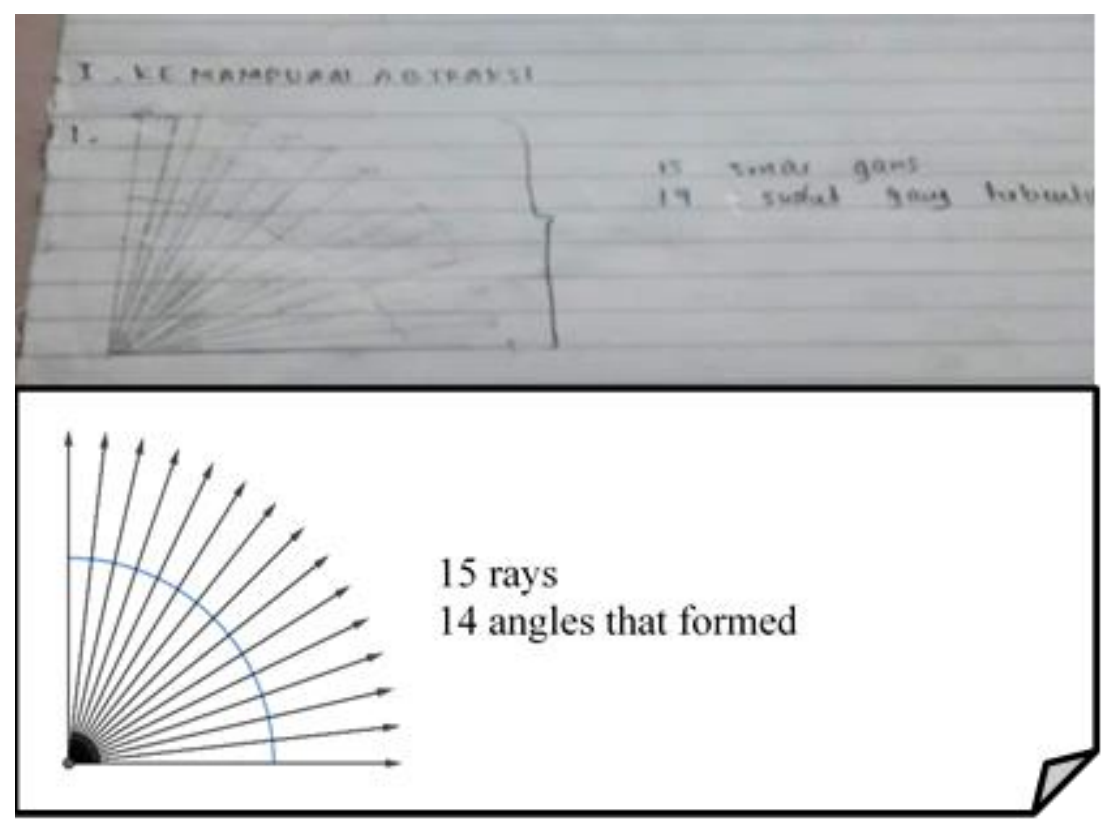

Figure 3. Written Answer from Subject 2

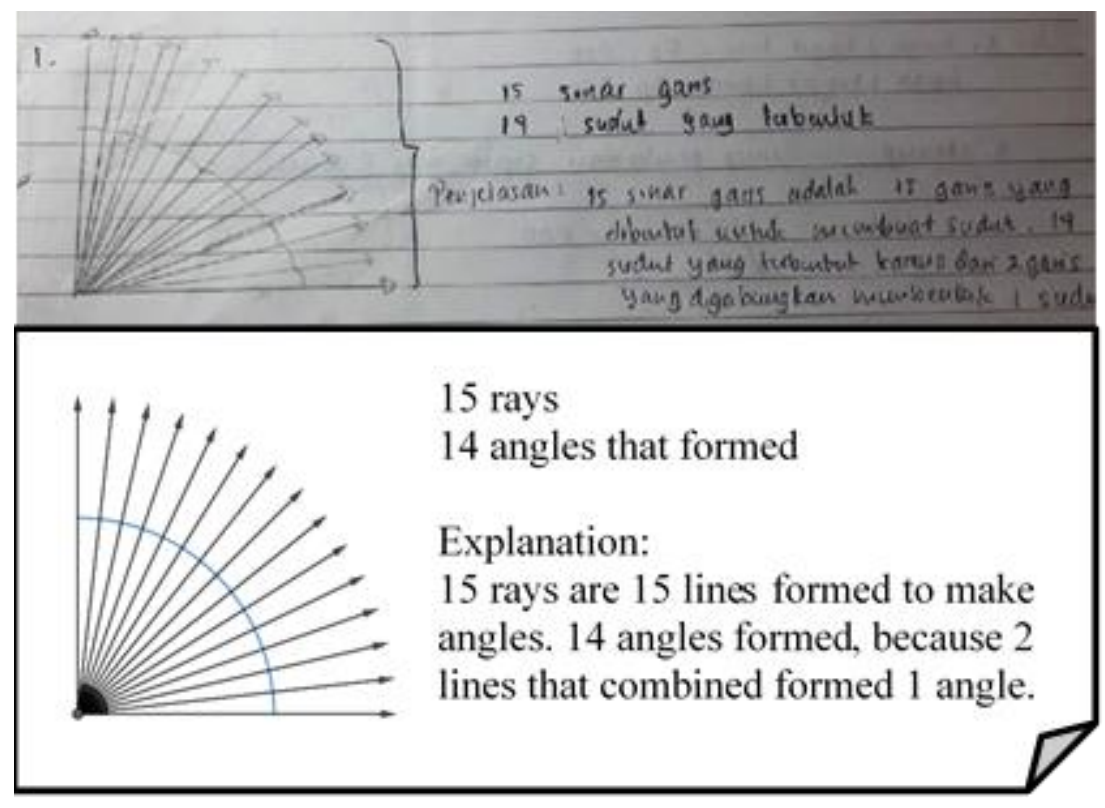

Figure 4. Interview Answer Sheet from Subject 2

The reason for answering 14 was because 2 lines joined together to form an angle, hence many lines were reduced to 1 . From this answer, it appeared that S2 only answered based on the drawings without considering other possible angles formation, not $3-1=2$ angles. S2 solved the problem using only the concept of an angle is formed from two lines that coincide at the same starting point. This meant that S2 integrated the problem structure with the available schemes, therefore seeing only 14 possible angles. The thinking process that combines its schemes with problem structures according to Piaget and Inhelder (1969), as well as Blake and Pope (2008) is called assimilation. 
Subject 3 (S3) was a student that answered according to figure 5. The person stated any 60 angles that formed from 15 lines had the same starting point. Because S3 also explained how to obtain the answer, an interview was conducted.

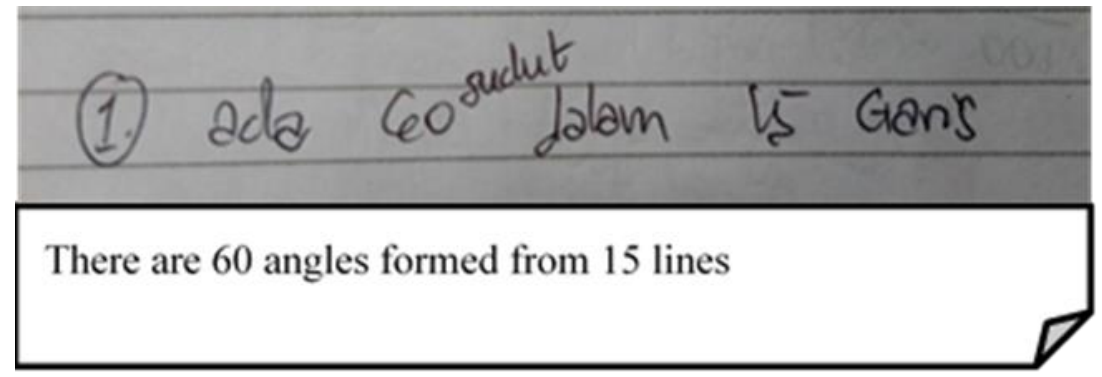

Figure 5. Answer from Subject 3

During the interview, S3 felt the answer provided was wrong and this is shown in Figure 6.

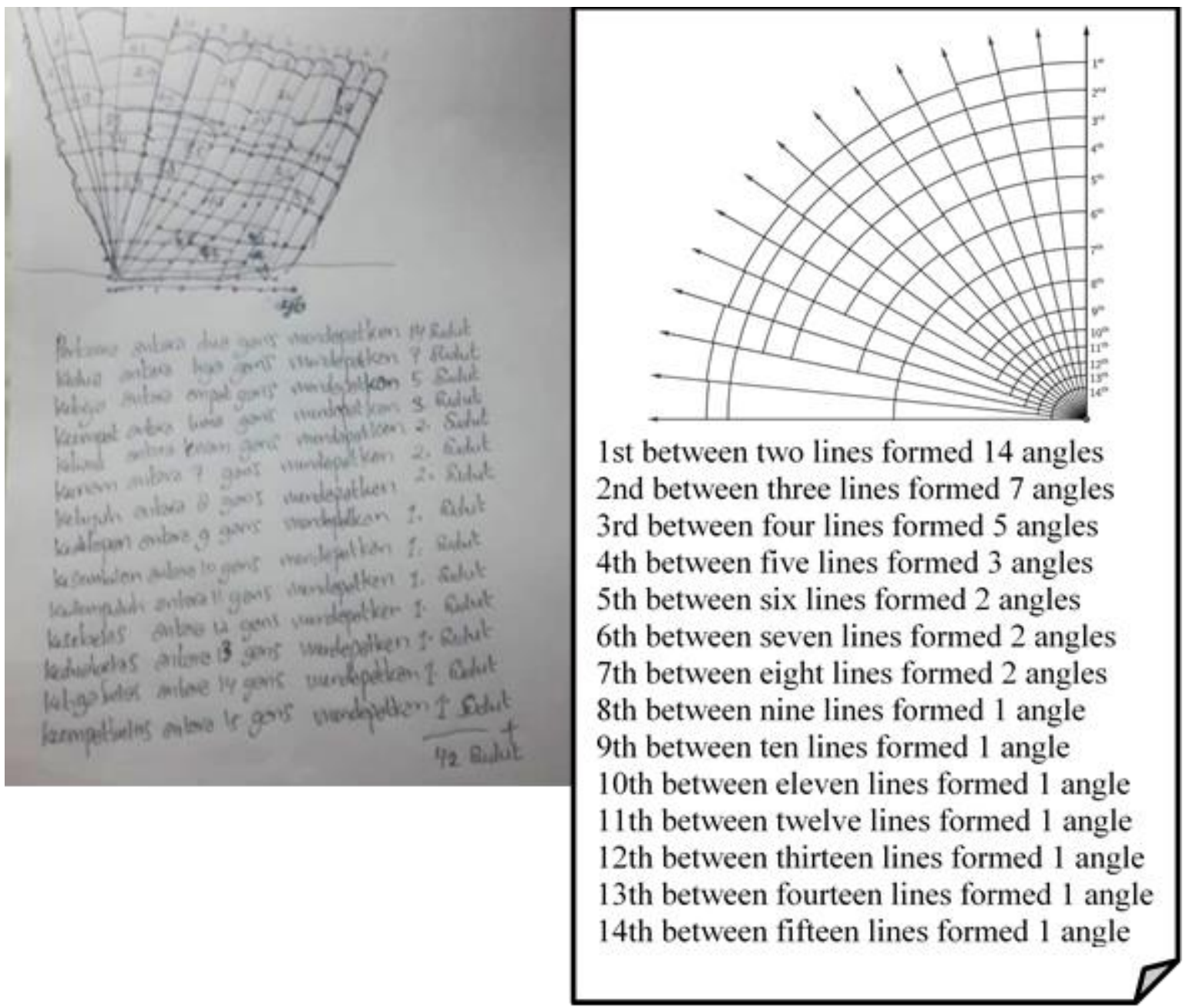

Figure 6. Interview Answer Sheet from Subject 3

S3 explained that when two lines form one angle, then 14 angles are formed from 15 lines. But, when three lines form one angle, then 7 angles are formed from 15 coincided lines. From the S2's answer, the drawn lines were viewed as not being utilized anymore in the calculations. However, S3 used critical thinking to solve the problem. When asked why the answer was different from that of S2, S3 said it was due to wrong counting, and when asked of other ways to solve the problem, S3's response was no. From the written answers and interviews, S3 did not guess the answers, but made pictures as visualization aids and discovered many possible solutions. 
Subject 4 (S4) solved the problem using pictures and the results were 106 angles but provided no reason on how to obtain these answers and this can be seen in Figure 7.

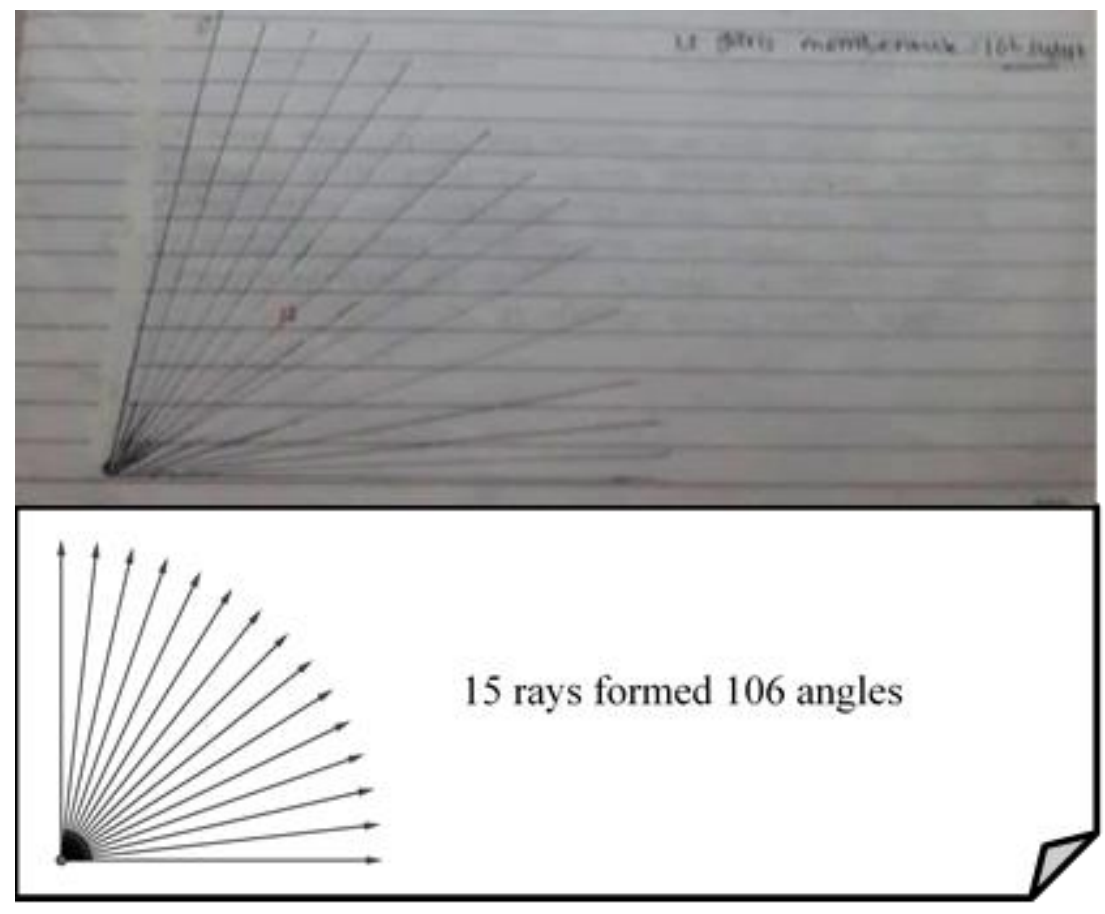

Figure 7. Written Answer from Subject 4

The results of the interview with $\mathrm{S} 4$ can be seen in Figure 8. Out of the 33 students subjected to the written test, only S4 used a number pattern to solve the problem, even though being wrong yet it was a support for the answer.

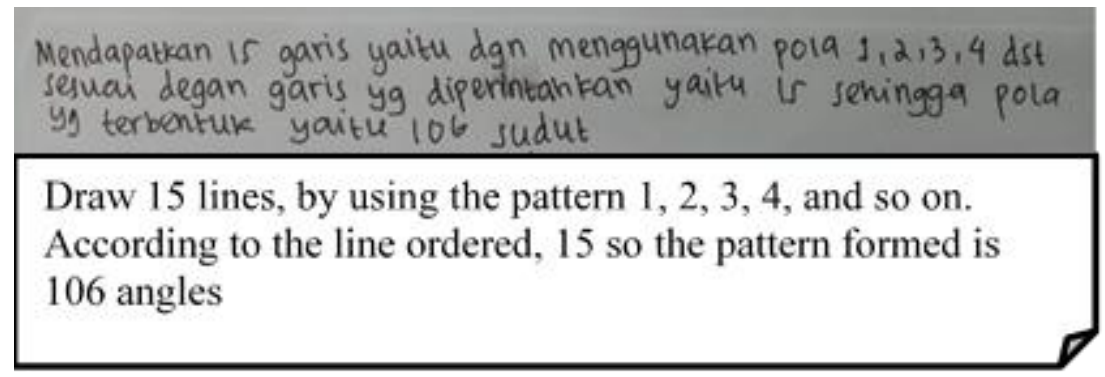

Figure 8. Interview Answer Sheet from Subject 4

According to S4, the 106 angles were formed from making 15 lines, with patterns 1, 2, 3, 4, etc. When asked that "is the picture you made used to solve the problem"? S4 said no. Next, the question was "why did you not use that picture"? S4 said it was easier to use the patterns. Therefore, S4 believed a problem can be solved by drawing and using shaped angular patterns. 


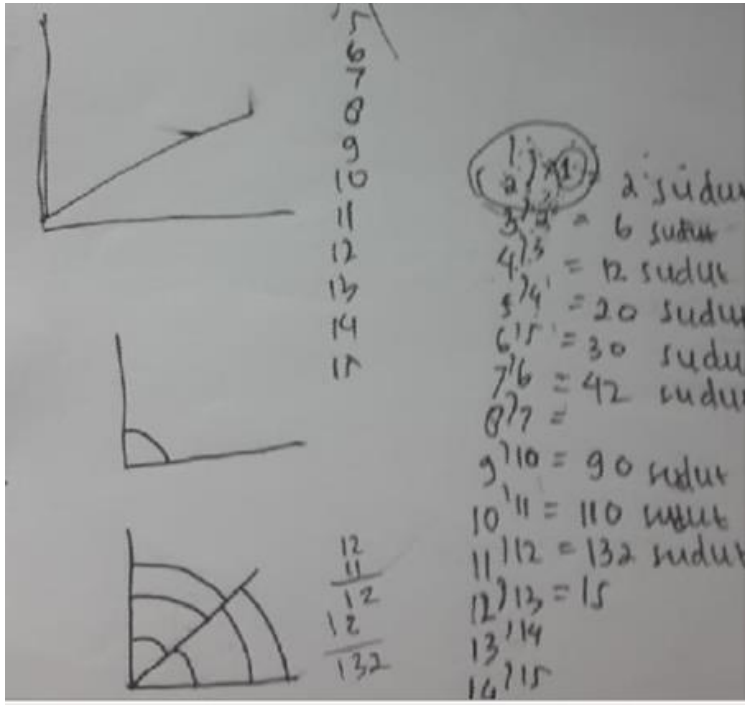

Figure 9. Interview Answer Sheet from Subject 4

According to figure 9, when answering the question, S4 made a pattern of lines to form many angles. After counting to the 10th line, S4 realized being wrong and he complained of forgetting how to count and because of visible nervousness, (reddish face), S4 was not told to recalculate. According to Ashcraft and Kirk (Walker, 2007), the anxiety effect on mathematical cognition shows a decreased problem solving due to the lack of effective working memory space, and this situation happened to S4. But when asked of the reason for not using the image made like in Figure 7, S4 tried and said "it was hard, it was easier to use patterns". The answer resolved mathematical abstraction problems associated with angles possible to be formed. Mitchelmore \& White (2007) it was difficult for students to identify angles in slopes and turns, where one or both arms of the angle have to be imagined or remembered.

Subject 5 (S5) was the students that did not give numerical answers but drawn the number of angles possible to be formed without explanation. The written test answers can be seen in Figure 10.
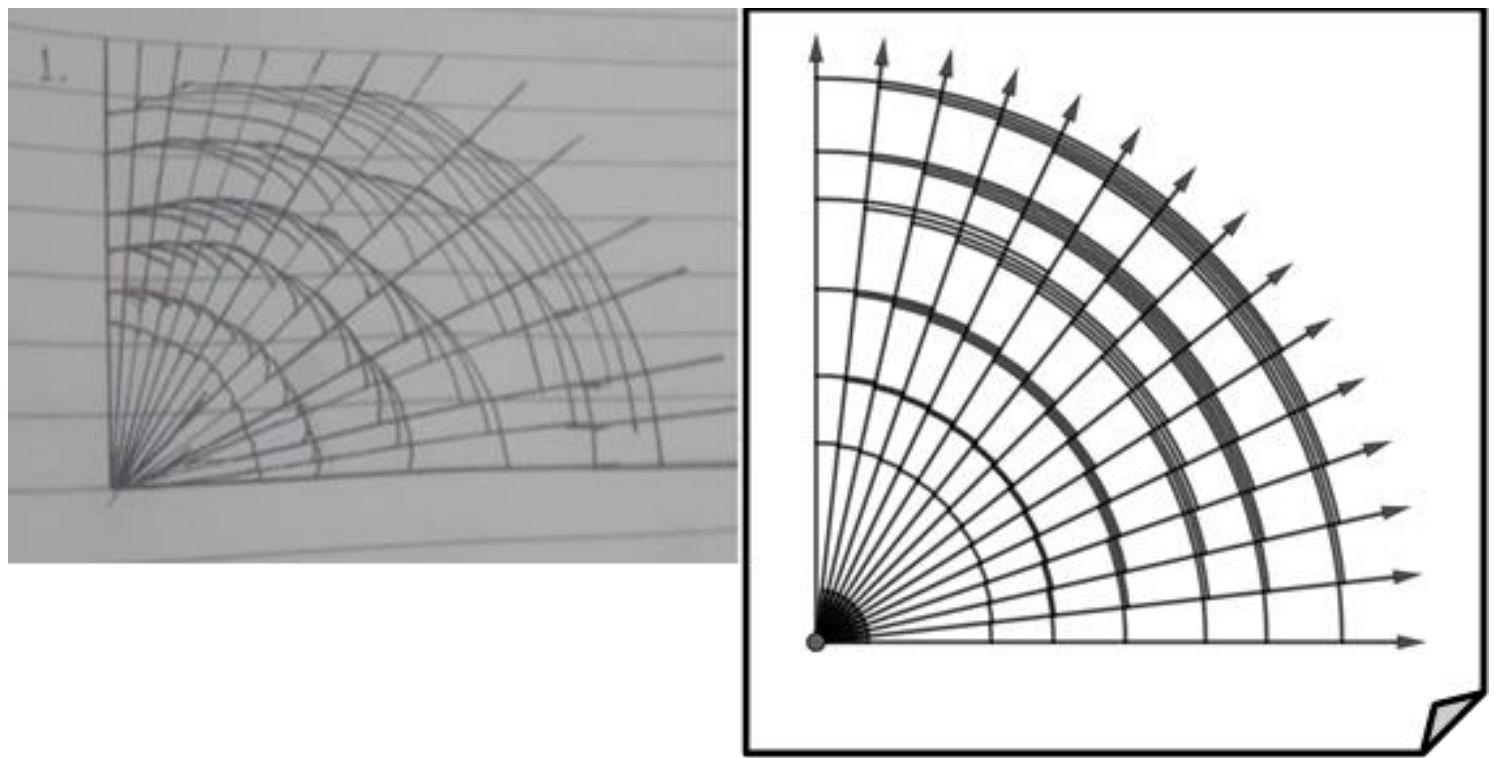

Figure 10. Written Answer from Subject 5

When asked during the interview, S5 said the curve at the bottom showed the possible angle to form from two lines. Furthermore, the curves in the second line showed the number of angles that can be formed from three lines. Also, the explanation provided by S4 was similar to Figure 11. 


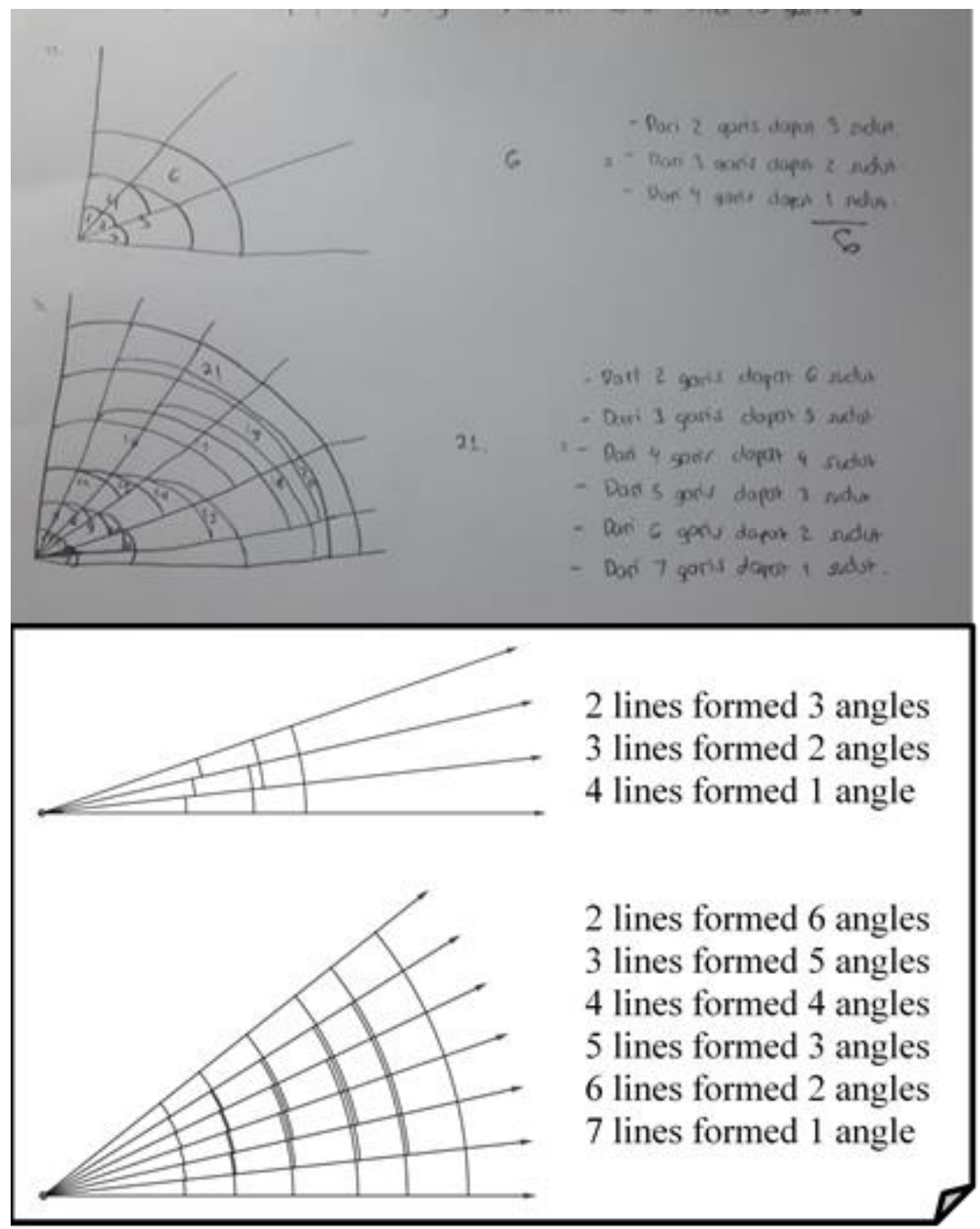

Figure 11. Interview Answer Sheet from Subject 5

S5 stated 6 angles are potentially formed from 4 lines that coincide at the same base.

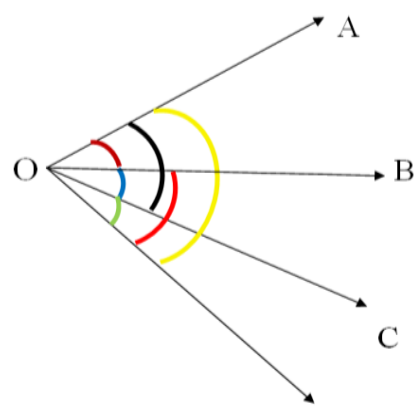

D

Figure 12. Answer from Subject 5

In case there were 7 lines, 21 angles that are possible to be formed. The method used by S5 led to the correct answer, but S5 did not calculate all the angles possible to be formed from 15 lines that coincided at one starting point. This was because S5 solved the problem using only images without mathematical induction assistance. When asked of other ways to solve the problem, S5's response was no. Yet to answer the question, S5 only needed to make 5 lines and then obtain a pattern of numbers from the angles formed as below.

From 2 lines forming 1 corner 


$$
\begin{aligned}
& 3 \text { lines }=>2+1=3 \text { angles } \\
& 4 \text { lines }=>3+2+1=6 \text { angles } \\
& 5 \text { lines }=>4+3+2+1=10 \text { angles, }
\end{aligned}
$$

Therefore, the pattern of numbers obtained are as follows

$$
\begin{array}{lllll}
0 & 1 & 3 & 6 & 10
\end{array}
$$

The results showed from S1 to S5, no student answered correctly, but only S1 provided reasons for their answers during the written test. Generally, in solving mathematical abstraction problems, the students did not discover an easy way to solve each problem, but used, for example, a pattern which is difficult to perform. In mathematics, learning patterns now known as formulas is very necessary. Similar to the above representations, the abstraction problem from the pattern of the angles' number are $0,1,3,6,10$, etc., which form the formula $\frac{1}{2} n(n-1)$. This is because the subjects were still in grade 7 and certainly unable to find the formula, but used patterns and mathematical critical thinking.

In solving a problem effectively, students need to consider the ability to use knowledge, facts and data. The ability to use knowledge and facts to solve problems is a characteristic of critical thinking and this is needed to ensure the students think personally, assess problems encountered and find solutions. Critical thinking in the learning process is one of the skills that deliver generalization (Hashemi: 2011). It also accustoms students to have the willingness to determine relevant information and perform flexible thinking when conducting an evaluation (Thompson: 2011). Sue, Ricci, and Mamikon (2016) reported that critical thinking was the second most important after interpersonal skills.

\section{Conclusion}

Based on the explanations, it can be concluded that the strategies and thinking processes used in solving the mathematical abstraction problems were guessing and drawing. Also, students did not maximize their critical thinking skills therefore they were unable to solve problems correctly.

\section{Recommendation}

Based on the explanations, it can be concluded that the strategies and thinking processes used in solving the mathematical abstraction problems were guessing and drawing. Also, students did not maximize their critical thinking skills therefore they were unable to solve problems correctly.

\section{References}

1. Blake, B., \& Pope, T. (2008). Developmental Psychology: Incorporating Piaget's and Vygotsky's Theories in Classrooms. Journal of Cross-Disciplinary Perspectives in Education, 1 (1), 59-67.

2. Ferrari P.L. (2003). Abstraction in Mathematics. The Royal Society Publishing, retrieved in April 2018 from http://rstb.royalsocietypublishing.org/content/358/1435/1225.

3. Hashemi, A. S. (2011). The Use of Critical Thinking in Social Science Textbooks of High School: A Field Study Of Fars Province In Iran. Journal International of Instruction, 4, 53-63.

4. Miller, S.P., \& Mercer, C.D. (1993). Using data to learn about concrete-representational-abstract instruction for students with math disabilities. Learning Disabilities Research and Practice, 8, 89-96.

5. Mitchelmore, M., White, P. (2007). Abstraction in Mathematics Learning. Mathematics Education Research Journal, 19(2), 1-9.

6. Piaget, J., \&Inhelder, B. (1969). The Psychology of the Child. London: Routledge \& Kegan Paul.

7. Sheffield, L. J. dan Cruikshank, D. E. (1996). Teaching and Learning; Elementary and Middle School. New Jersey: Prentice Hall, Inc.

8. Su, H. F. H.; Ricci, F. A.,Mnatsakanian, M. (2016). Mathematical Teaching Strategies: Pathways to Critical Thinking and Metacognition. International Journal of Research in Education and Science, 2(1), 190-200.

9. Thompson, C. (2011). Critical Thinking Across the Curriculum: Process Over Output.Journal International of Humanities And Social Science, 9, 80-100.

10. Walker, C.M. (2007). An Investigation of How African American Community College Students with Different Levels of Mathematics Anxiety Engage in Problem Solving Tasks. 